Supplementary information.

\title{
Cockayne Syndrome B protein selectively interacts and resolves intermolecular DNA G-quadruplex structures.
}

Denise Liano ${ }^{\mathrm{a}, \mathrm{b}}$, Souroprobho Chowdhury ${ }^{\mathrm{a}, \mathrm{b}}$ and Marco Di Antonio ${ }^{\mathrm{a}, \mathrm{b}, \mathrm{c}^{*}}$

a Chemistry Department, Imperial College London, Molecular Science Research Hub, 82 Wood Lane, London, W12 OBZ, United Kingdom.

${ }^{b}$ Institute of Chemical Biology, Molecular Science Research Hub, 82 Wood Lane, London, W12 0BZ, United Kingdom.

${ }^{c}$ The Francis Crick Institute, London, NW1 1AT, United Kingdom.

${ }^{*}$ Corresponding author

Email: m.di-antonio@imperial.ac.uk 

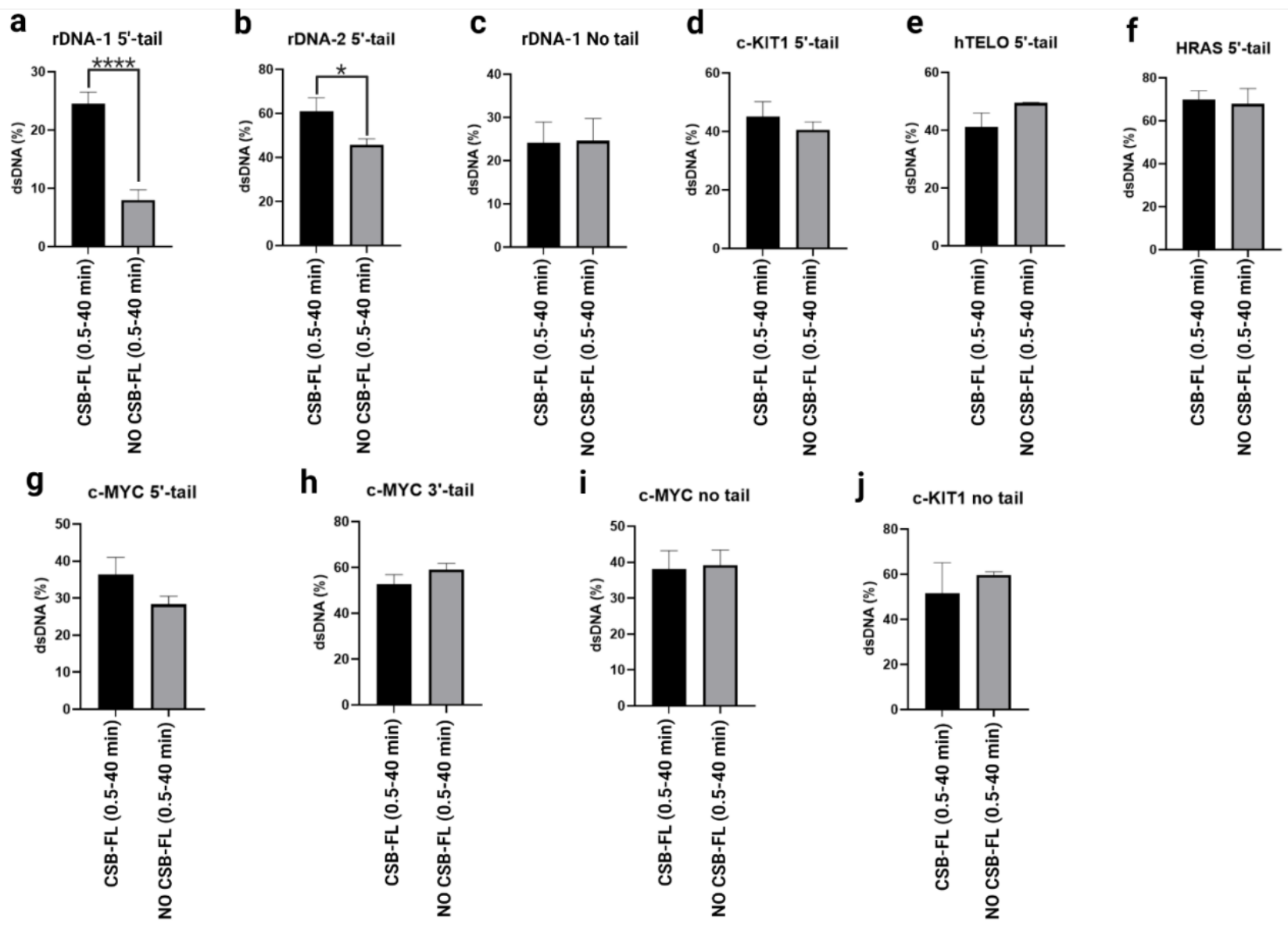

Figure S1. CSB selectively resolves tailed rDNA G4s. Column graph of quantified gel-based resolvase assays with or without CSB-FL in $\mathrm{KCl}$ buffer. The results are expressed as percentage of dsDNA formation. (a) 5'-tail rDNA-1. (b) 5'-tail rDNA-2. (c) Untailed rDNA-1. (d) 5'-tail c-KIT1. (e) 5'tail hTELO. (f) 5'-tail HRAS. (g) 5'-tail c-MYC. (h) 3-tail c-MYC. (i) Untailed c-MYC. (j) Untailed cKIT1. See Table S1 for the sequences used. All quantified gel-based resolvase assays were based on the average of three independent experiments. Significance was calculated based on two-tailed Student's t-test. Asterisks indicate statistical significance at $95 \% \mathrm{Cl}$ between the data with ${ }^{* * *} \mathrm{p}$ $<0.0001$ and ${ }^{*} \mathrm{p}<0.05$. 

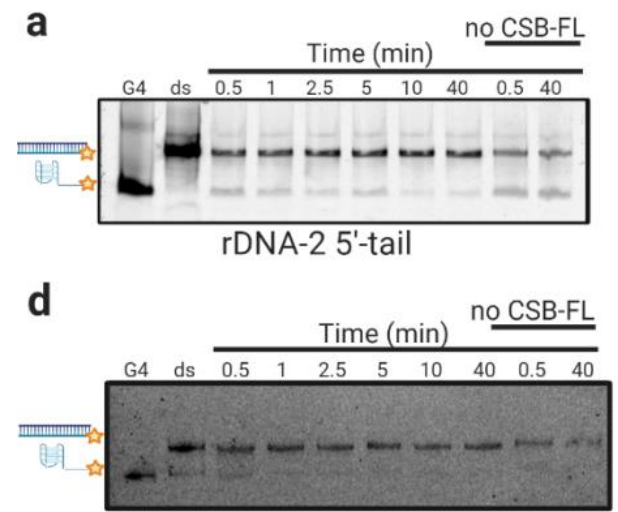

hTELO 5'-tail

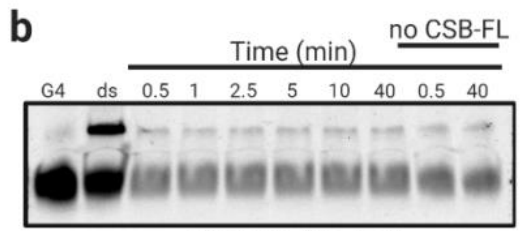

rDNA-1 No tail

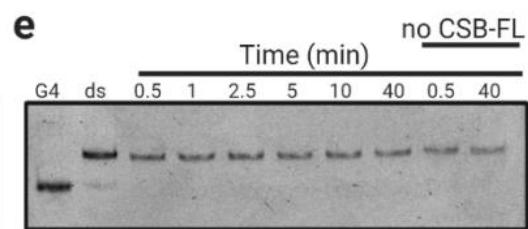

HRAS 5'-tail

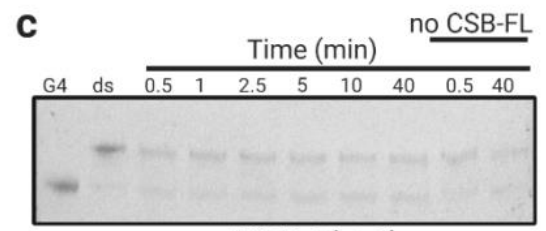

cKIT1 5'-tail

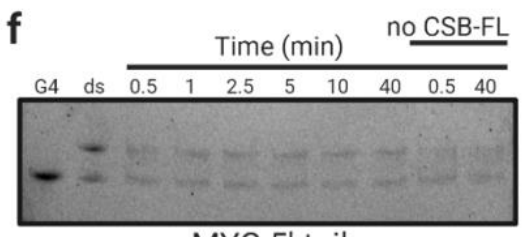

cMYC 5'-tail g

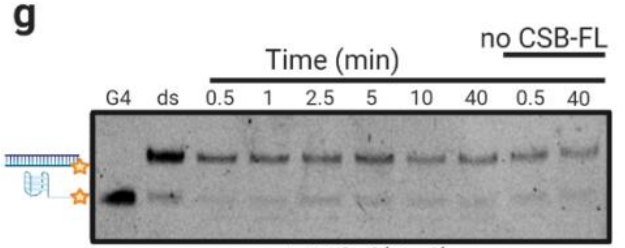

cMYC 3'-tail

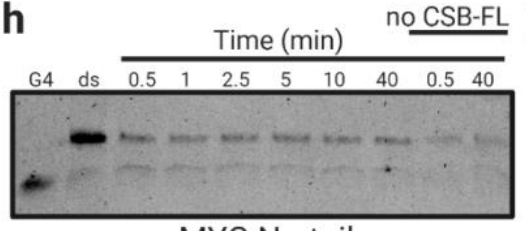

cMYC No tail

no CSB-FL

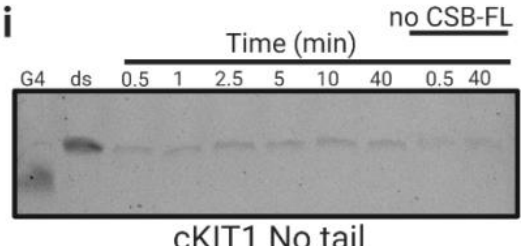

cKIT1 No tail

Figure S2. Gel-based resolvase assays performed with CSB-FL. Resolvase assay PAGE gels using different G4-forming sequences or non G4-forming sequences after incubation with (lanes 3 to 8) or without (lanes 9 and 10) CSB-FL for increasing time. See Table S1 for the sequences used. (a) 5'-tail rDNA-2. (b) Untailed rDNA-1. (c) 5'-tail c-KIT1. (d) 5'-tail hTELO. (e) 5'-tail HRAS. (f) 5'-tail c-MYC. (g) 3-tail c-MYC. (h) Untailed c-MYC. (i) Untailed c-KIT1. 
a

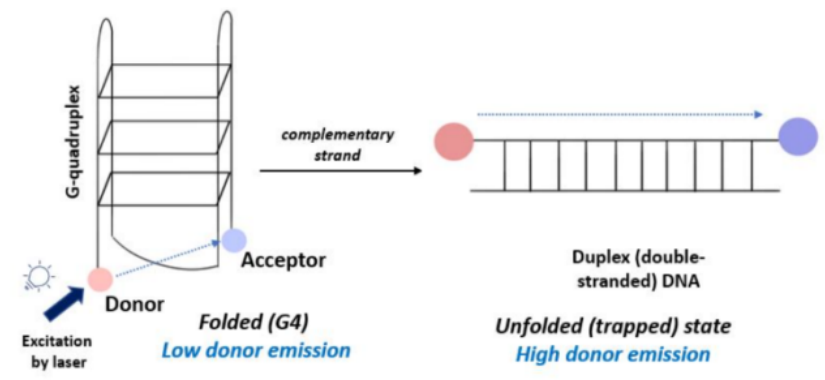

b

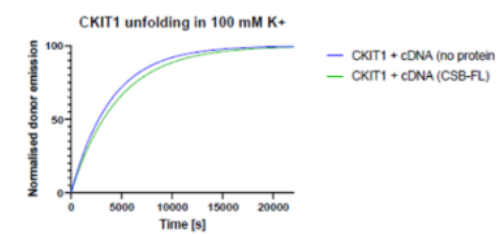

d
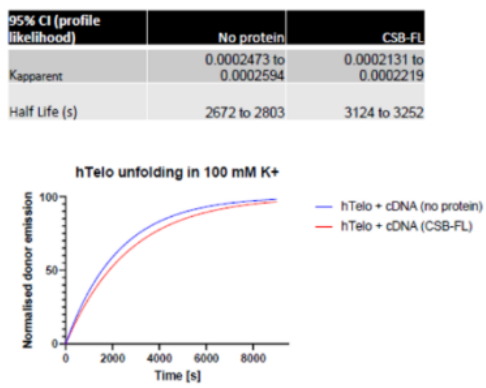

C

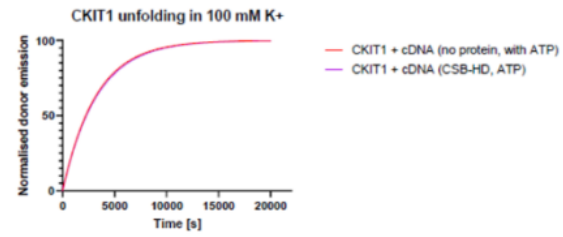

e
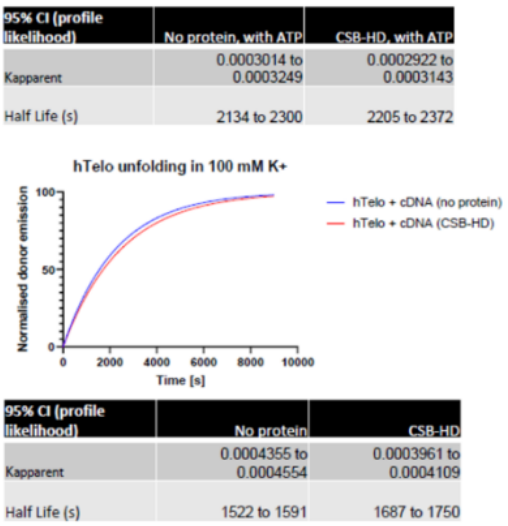

Figure S3. Panel of FRET-based unfolding traces. (a) Schematic representation of the FRET assay used to monitor G4-unfolding. (b, c) Unfolding traces obtained using CSB-FL and CSB-HD respectively incubated with a parallel intramolecular G4 (C-KIT1). (d, e) Unfolding traces obtained using CSB-FL and CSB-HD respectively, incubated with intramolecular mixed-type G4 (hTELO). See Table S1 for the sequences used. All experiments were performed in triplicates. Curves represent best-fit from single-exponential curve-fitting to triplicate data. Half-lives expressed in seconds as 95\% credible interval profile likelihood (computed using Graphpad Prism), with constraints set as $\mathrm{y} 0=0$, and plateau at 100 . 


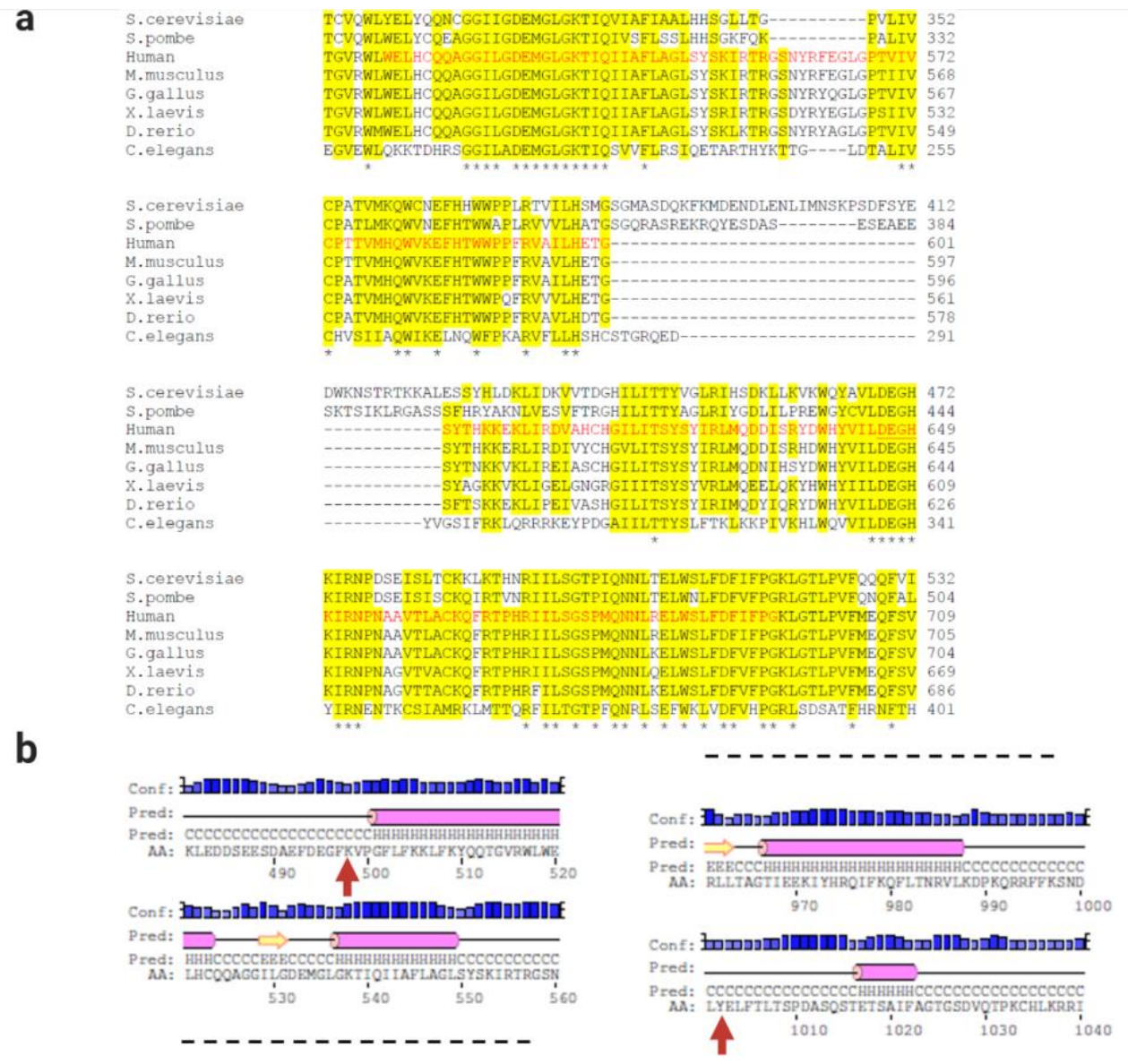

Figure S4. CSB-HD sequence identification. (a) Sequence alignment of the putative CSB helicase-like domain between different organisms (Clustal Omega, EMBL-EBI). In red is reported the human ATPase domain containing the DEGH box (646-649, highlighted in red). Asterisks indicate $100 \%$ identity between the residues. Yellow indicates identical or similar residues. (b) Portion of the secondary structure prediction (PSIPRED 4.0) of the selected human helicase-like domain of CSB (498-1002 aa). The red arrows indicate the first N-terminal amino acid (K-498) and the last C-terminal residue (Y-1002). The $\alpha$-helices are represented as pink cylinders while the $\beta$ coils are reported as yellow arrows. 
a

rDNA-1 5'-tail
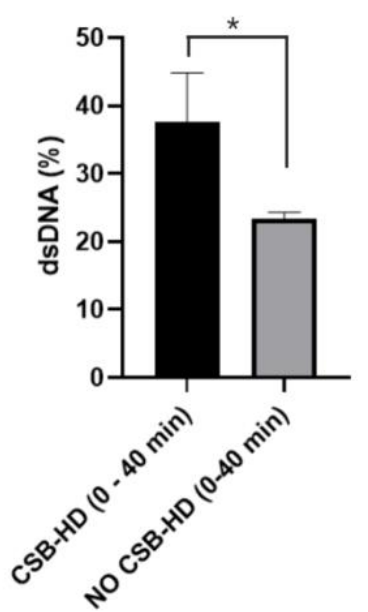

b

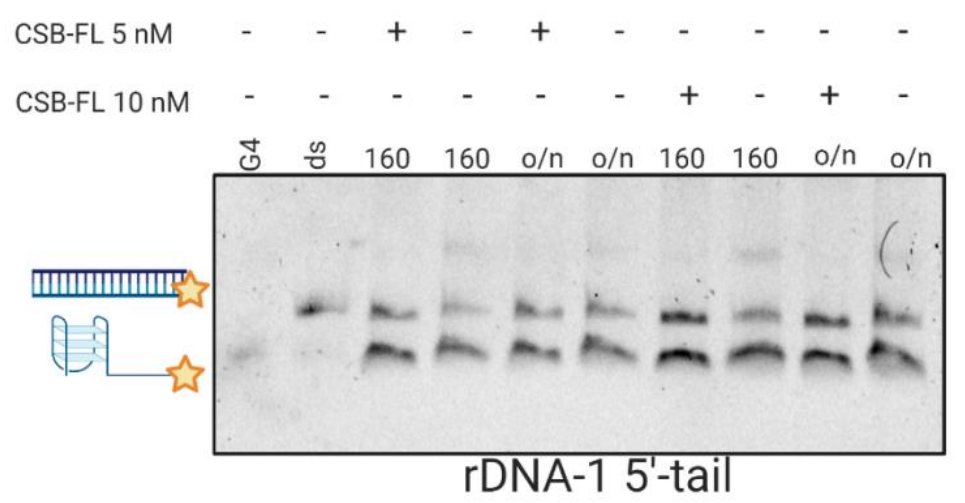

C
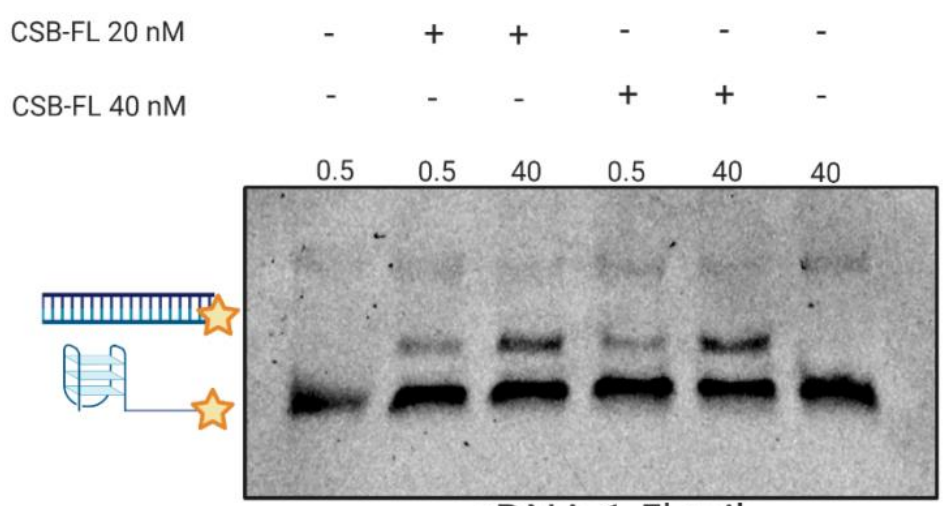

rDNA-1 5'-tail

Figure S5. CSB-HD retains the same activity as the FL protein which is independent on incubation times or CSB concentrations. (a) Column graph of quantified 5'-tail rDNA-1 gel-based resolvase assay with or without CSB-HD in $\mathrm{KCl}$ buffer. The results are expressed as percentage of dsDNA formation. See Table S1 for the 5'-tailed rDNA-1 sequence used. All quantified resolvase assays were based on the average of three independent experiments \pm SEM. Significance was calculated based on two-tailed Student's t-test. Asterisks indicate statistical significance at $95 \% \mathrm{Cl}$ between the data with ${ }^{*} p<0.05$. (b) Gel-based resolvase assay gel in presence or absence of either $5 \mathrm{nM}$ or $10 \mathrm{nM}$ CSB-FL after 160 min or overnight (o/n) incubation time. (c) Resolvase assay gel in presence of either $20 \mathrm{nM}$ or $40 \mathrm{nM}$ CSB-FL after 0.5 min or 40 min incubation time. 
a

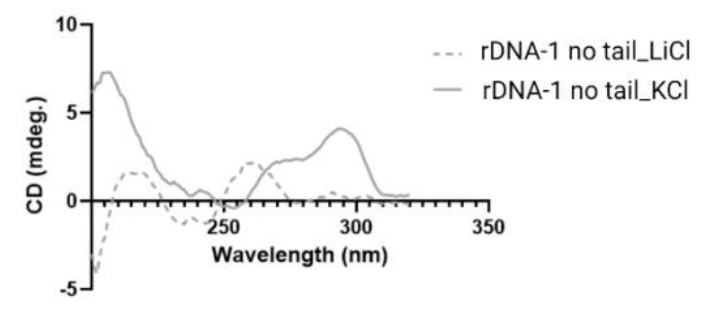

C

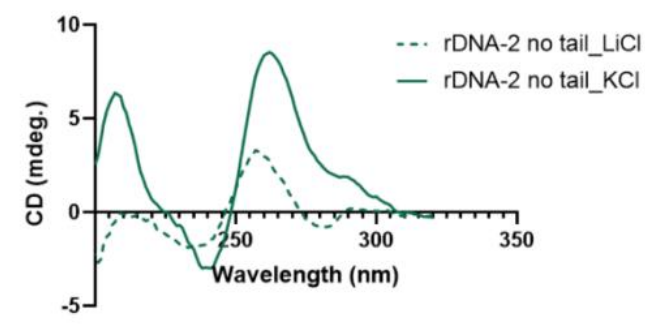

e

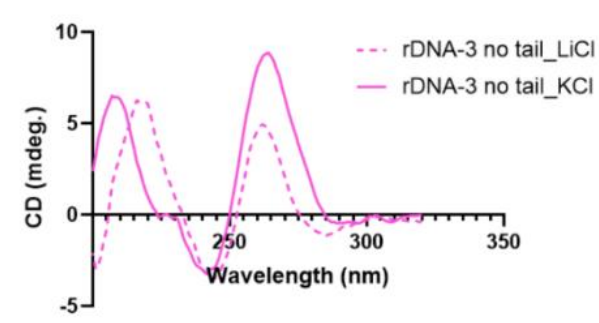

b

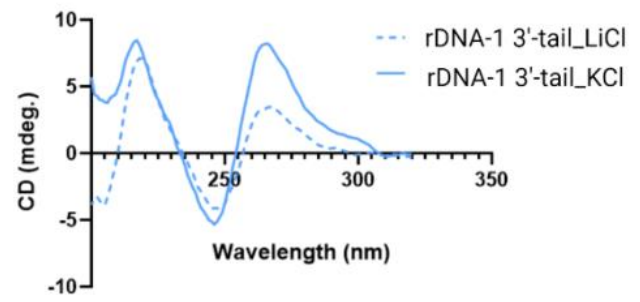

d

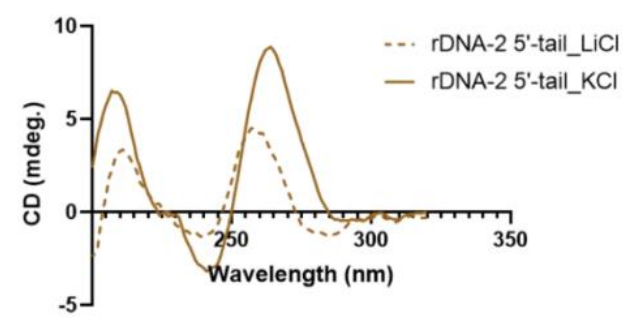

f

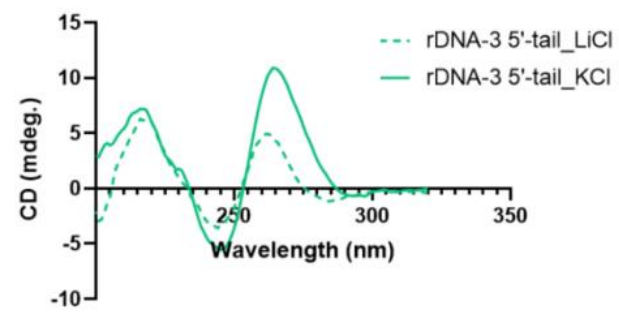

Figure S6. Circular dichroism (CD) analysis of the different rDNA sequences in $\mathrm{LiCl}$ or $\mathrm{KCl}$ buffer. (a) CD spectra rDNA-1 No tail. (b) CD spectra rDNA-1 3'-tail. (c) CD spectra rDNA-2 No tail. (d) CD spectra rDNA-2 5'-tail. (e) CD spectra rDNA-3 No tail. (f) CD spectra rDNA-3 5'-tail. See Table S1 for the sequences used. The recorded spectra represent the average of three different reads corrected by using the CD-spectra of buffer alone as a blank. 


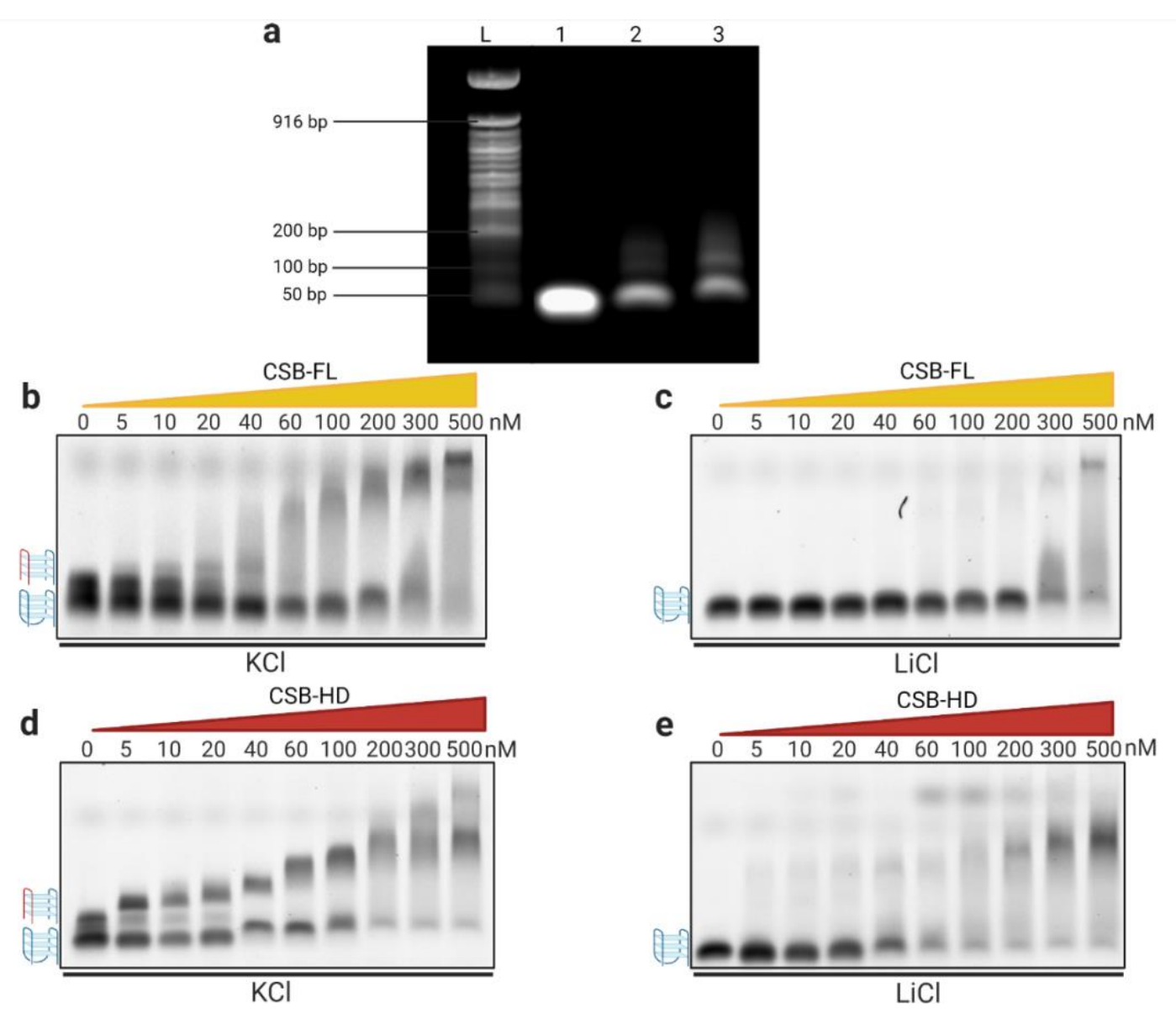

Figure S7. EMSA in agarose revealed the formation of multimeric rDNA G4s formation. (a) Agarose gel of unlabelled 5'-tail rDNA-1 substrate annealed in buffer containing: L: ladder, 100mM $\mathrm{LiCl}(1), 100 \mathrm{mM} \mathrm{KCl}$ (2) or $100 \mathrm{mM} \mathrm{KCl}+30 \%$ PEG200 (3). (b) EMSA gel using high concentration (0 to $500 \mathrm{nM}$ ) CSB-FL in presence of 5'-tail rDNA-1 in $\mathrm{KCl}$ buffer. (c) EMSA gel using high concentration (0 to $500 \mathrm{nM}$ ) CSB-FL in presence of 5'-tail rDNA-1 in LiCl buffer. (d) EMSA gel using high concentration (0 to $500 \mathrm{nM}$ ) CSB-HD in presence of 5'-tail rDNA-1 in KCl buffer. (e) EMSA gel using high concentration ( 0 to $500 \mathrm{nM}$ ) CSB-HD in presence of 5'-tail rDNA-1 in LiCl buffer. See Table S1 for the 5'-tail rDNA-1 sequence used. Unimolecular G4s are indicated with blue strands while multimeric G4s are indicated with red and blue strands. 
a

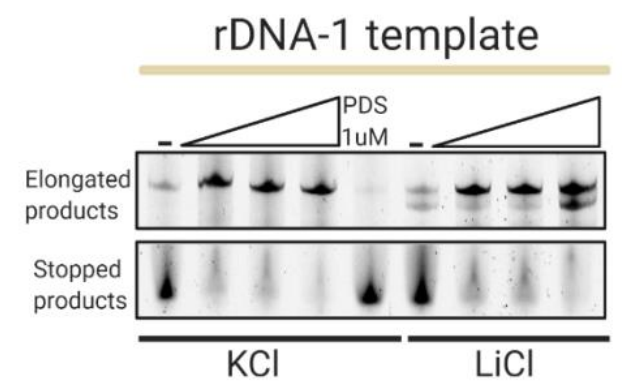

C

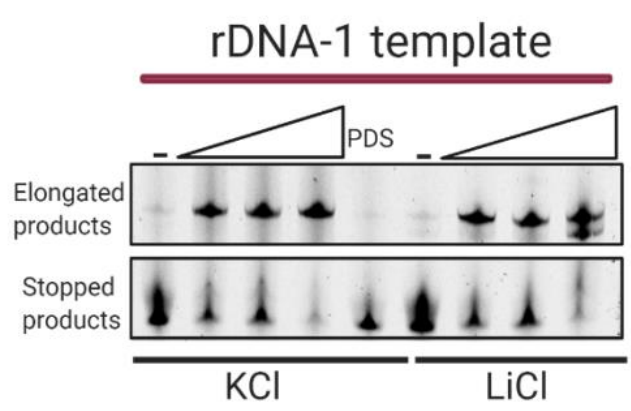

b

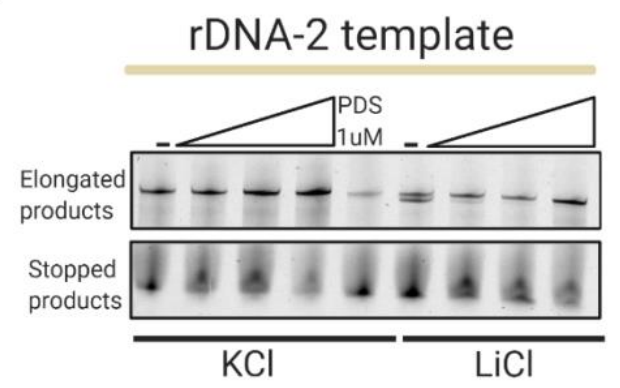

d

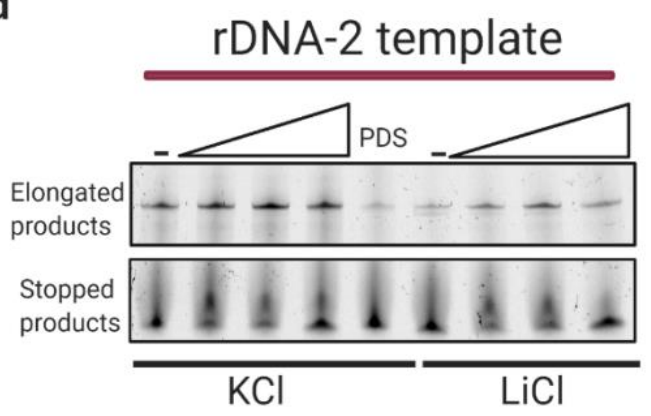

Figure S8. Polymerase stop assays indicating polymerase arrest at the level of the rDNA G4forming sequence both in $\mathrm{KCl}$ and $\mathrm{LiCl}$. (a, b) Experiment performed using either rDNA-1 or rDNA2 sequence either under $\mathrm{KCl}$ or LiCL in presence or absence (-) of increasing concentrations of CSBFL or pyridostatin (PDS). (c, d) Experiment performed using either rDNA-1 or rDNA-2 sequence either under $\mathrm{KCl}$ or $\mathrm{LiCL}$ in presence or absence (-) of increasing concentrations of CSB-HD or PDS. See Table S4 for the sequences and the primer used in these experiments. The products elongated by the polymerase run slower on the polyacrylamide gel as their size is bigger compared to the early stopped products which run at the bottom of the gel. PDS incubation is used as control to confirm the arrest of the polymerase elongation at the G4-forming site as indicated by formation of fully stopped products at the bottom of the gel. 
a

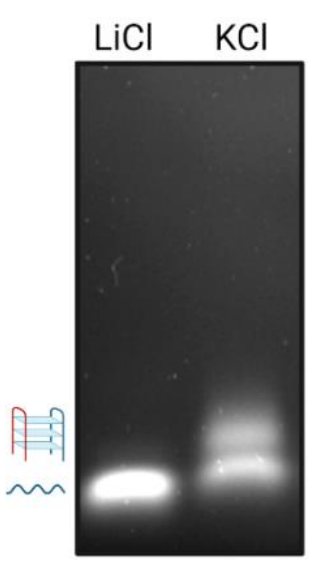

b

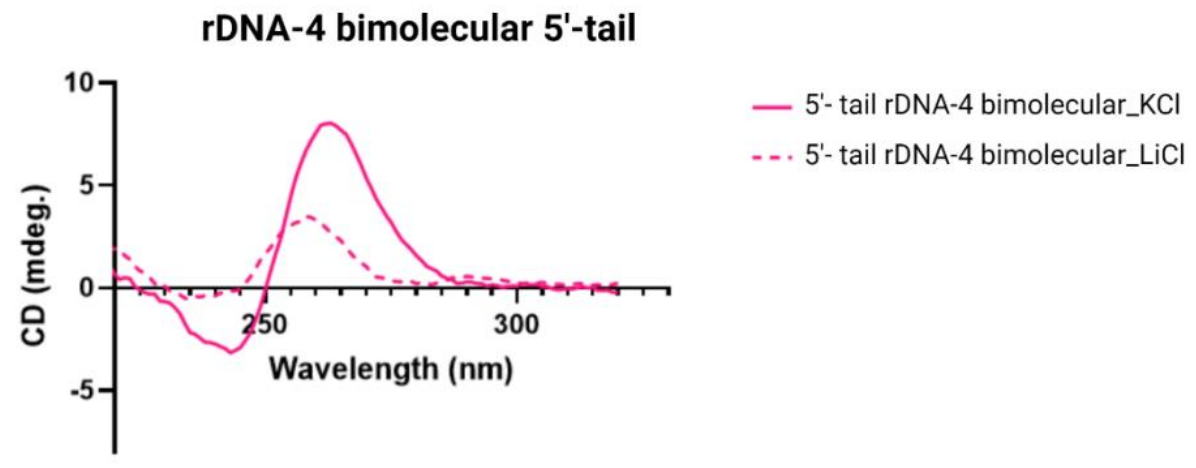

C

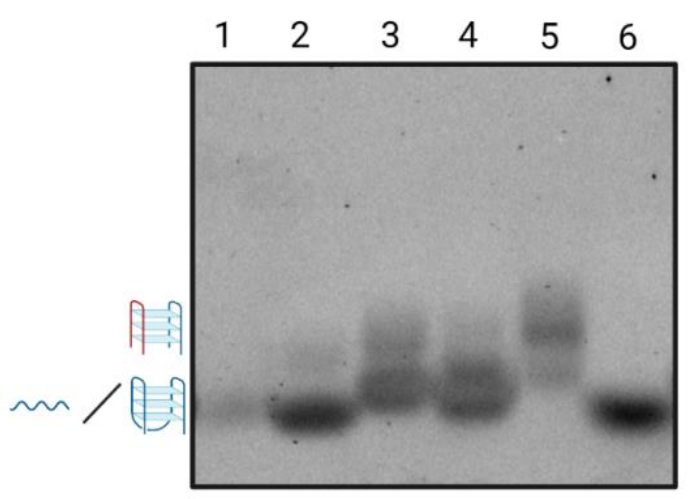

Figure S9. Intermolecular G4s can be formed by a truncated rDNA sequence that contains only three stretches of guanines. (a) Agarose gel of 5'- tail truncated bimolecular rDNA-4 sequence (5'-TAATAGGGGCCGGGGGTGGGGT-3') annealed either in LiCl or KCl. (b) CD spectra of the same 5'-tailed rDNA-4 bimolecular. The recorded spectra represent the average of three different reads. The absorbance of the buffers was subtracted from the recorded spectra. (c) NMM staining of agarose gel. Lane 1: ssDNA, Lane 2: untailed rDNA-1 in KCl buffer, Lane 3: 5'-tail rDNA1 in $\mathrm{KCl}$ buffer, Lane 4: 5'-tail rDNA-2 in $\mathrm{KCl}$ buffer, Lane 5: 5'-tail rDNA-3 in $\mathrm{KCl}$ buffer, Lane 6 : untailed rDNA-1 in LiCl buffer (see Table S1 and S4 for the sequences used in these experiments). ssDNA band is indicated with a blue linear strand, intramolecular G4s are indicated with blue strand while intermolecular G4s are indicated with red and blue strand. 


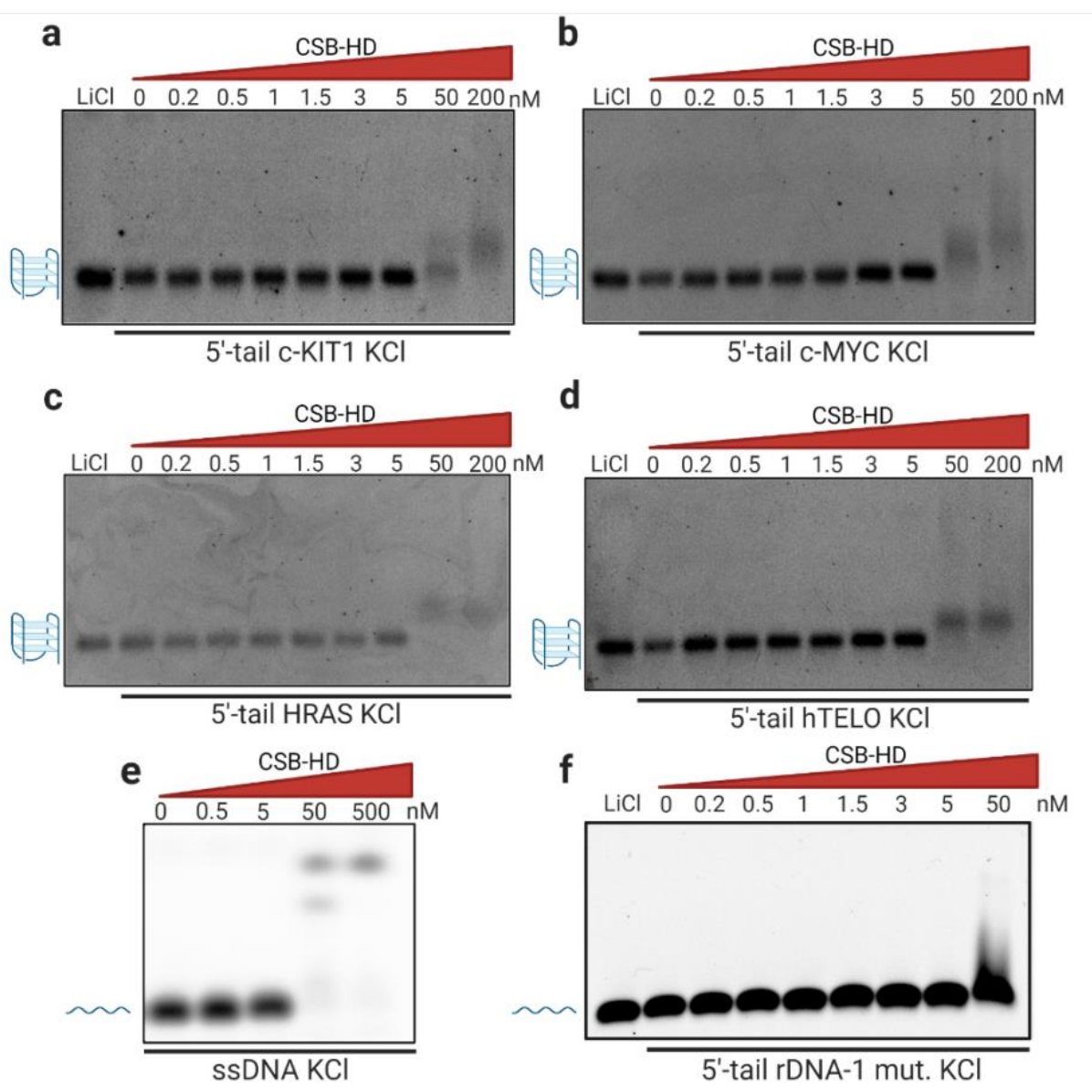

Figure S10. CSB does not bind non-rDNA G4s and G-rich single-stranded DNA sequences at low concentration. EMSA agarose gels obtained after incubation of increasing concentration of CSB-HD (0 to $5 \mathrm{nM}$ and 50-200 nM or 50-500 nM) with different non-rDNA G4 oligonucleotides under $\mathrm{KCl}$ conditions. (a) EMSA using 5'-tail c-KIT1. (b) EMSA using 5'-tail c-MYC. (c) EMSA using 5'-tail HRAS. (d) EMSA using 5'-tail hTELO. (e) EMSA using 5'-tail ssDNA as control. (f) EMSA obtained after incubation with increasing concentration of CSB-HD (0 to $50 \mathrm{nM}$ ) with a G-rich single-stranded DNA control in $\mathrm{KCl}$ (5'-tail rDNA-1 mut). See Table $\mathrm{S} 1$ and $\mathrm{S} 4$ for all the sequences used in these experiments. Unimolecular G4s are indicated as blue strand while ssDNA bands are indicated with a blue linear strand. 
a

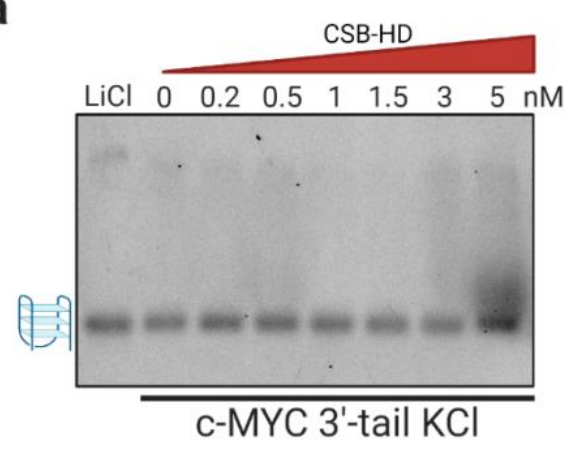

b

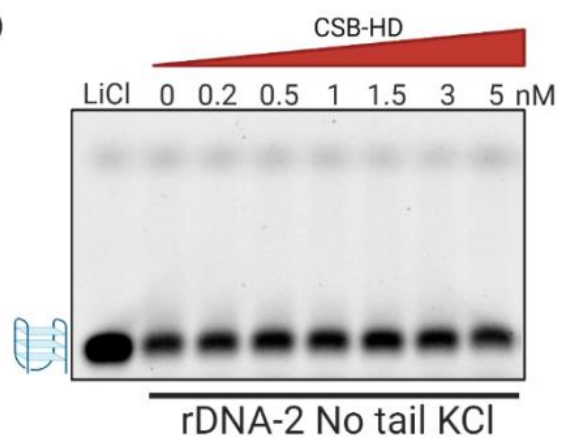

C

CSB-HD

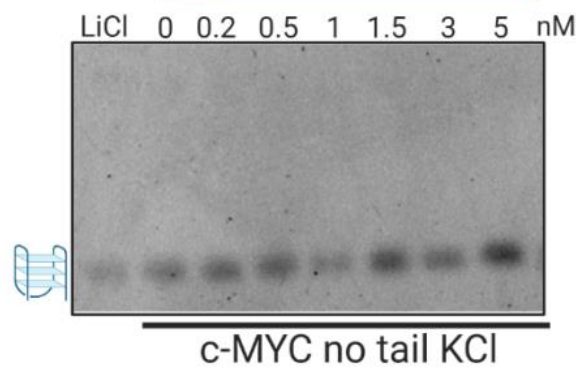

Figure S11. Intermolecular G4s cannot form within rDNA sequences in absence of a tail. EMSA agarose incubating increasing concentration of CSB-HD (0 to $5 \mathrm{nM})$ in presence of 3'-tailed intramolecular G4 or untailed oligonucleotides under $\mathrm{KCl}$ conditions. (a) EMSA using 3'-tail c-MYC. (b) EMSA using untailed rDNA-2. (c) EMSA using untailed c-MYC. See Table S1 for the sequences used. Unimolecular G4s are indicated as blue strand. 


\section{a}

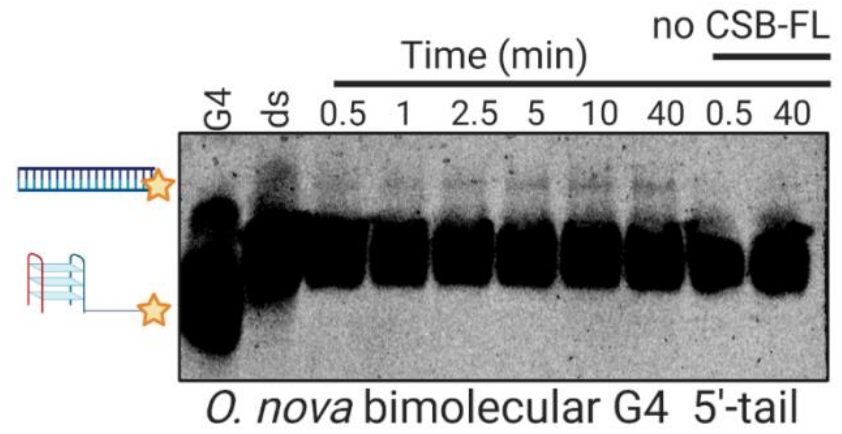

Figure S12. CSB selectively resolves bimolecular G4s. Gel based-resolvase assay gel in presence or absence of $10 \mathrm{nM} \mathrm{CSB}-\mathrm{FL}$ after 0.5 to 40 min incubation time. (a) Resolvase assay using 5'-tail O. nova G4. See Table S4 for the sequence used in this experiment. 
a

C
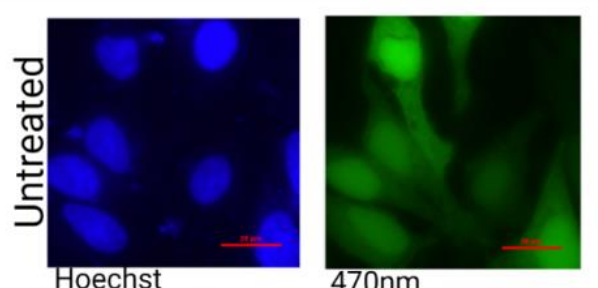

$470 \mathrm{~nm}$

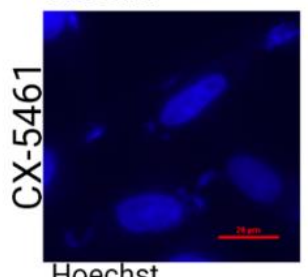

Hoechst
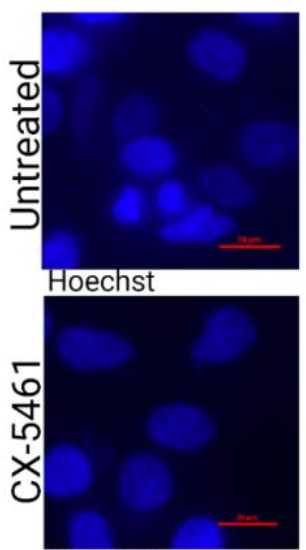

Hoechst

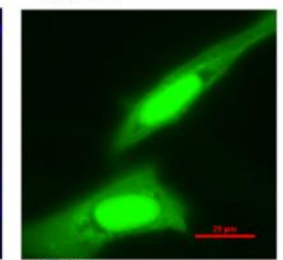

$470 \mathrm{~nm}$

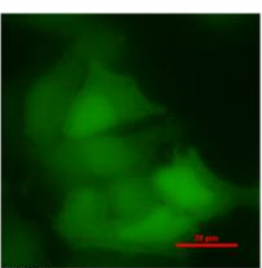

$470 \mathrm{~nm}$

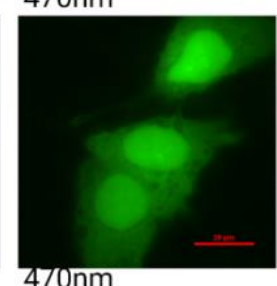

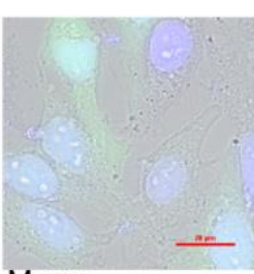

Merge

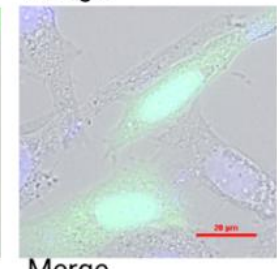

Merge

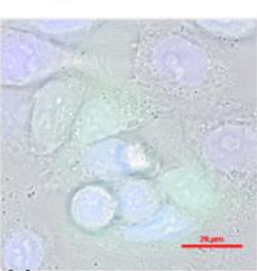

Merge

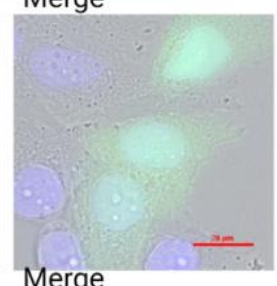

b

24 hours treatment

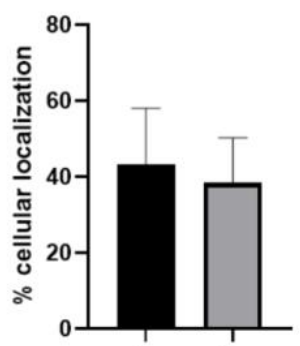

d

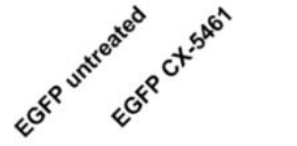

4 hours treatment

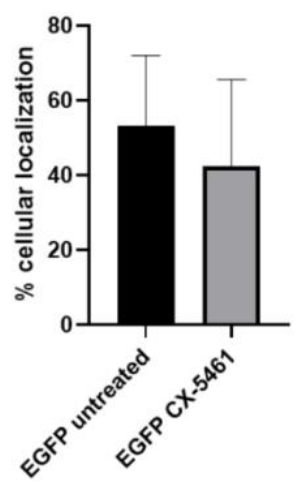

Figure S13. Treatment with CX-5461 did not affect the expression of the empty EGFP construct. (a) Localisation pattern of pEGFP-1C in HeLa cells without treatment with G4-ligands (Untreated) or after 24 hours treatment with CX-5461. Hoechst is the nuclear marker, 470nm indicates the EGFP signal and Merge is the overlap between all the signals. Bar: $20 \mu \mathrm{m}$. Quantification of the cellular localisation of pEGFP-1C without treatment with G4-ligands (EGFP untreated) or after 24 hours treatment with CX-5461 (EGFP CX-5461). (c) Localisation pattern of pEGFP-1C in HeLa cells without treatment with G4-ligands (Untreated) or after 4 hours treatment with CX-5461. (d) Quantification of the cellular localisation of pEGFP-1C without treatment with G4ligands (EGFP untreated) or after 4 hours treatment with CX-5461 (EGFP CX-5461). The percentage of cellular localisation was calculated from several cell images $(n=8)$ and each condition was performed in two biological and two technical replicates. Significance was calculated using paired two-way Student's t-test. 


\begin{tabular}{|c|c|}
\hline NAME & SEQUENCE $\left(5^{\prime} \rightarrow 3^{\prime}\right)$ \\
\hline (5'-Cy5) rDNA-1 5'-tail & ATAATTATAAATAAATAATGGGGCCGGGGGTGGGGTCGGCGGGGAAA \\
\hline Complementary rDNA-1 5'-tail & TTTCCCCGCCGACCCCACCCCCGGCCCCTATTATTTATTTATAATTAT \\
\hline (5'-Cy5) rDNA-2 5'-tail & ATAATTATAAATAAATAATAGGGTCGGGGGGTGGGGCCCGGGCCGGGG \\
\hline Complementary rDNA-2 5'-tail & CCCCGGCCCGGGCCCCACCCCCCGACCCTATTATTTATTTATAATTAT \\
\hline (5'-Cy5) rDNA No tail & GGGGCCGGGGGTGGGGTCGGCGGGGAAA \\
\hline Complementary rDNA No tail & TTTCCCCGCCGACCCCACCCCCGGCCCC \\
\hline (5'-FAM) c-KIT1 5'-tail & ATAATTATAAATAAATAATAGGGAGGGCGCTGGGAGGAGGGAAA \\
\hline Complementary c-KIT1 5'-tail & TTTCCСTCCTCCCAGCGCССTCССTTATTATTTATTTATAATTAT \\
\hline (5'-FAM) hTELO 5'-tail & ATAATTATAAATAAATAATGGGTTAGGGTTAGGGTTAGGGAAA \\
\hline Complementary hTELO 5'-tail & TTTCССТАAСССТАAСССТАAСССТАTTATTTATTTATAATTAT \\
\hline (5'-FAM) HRAS 5'-tail & ATAATTATAAATAAATAATATCGGGTTGCGGGCGCAGGGCACGGGCGAAA \\
\hline Complementary HRAS 5'-tail & TTTCGCCCGTGCCCTGCCCTGCGCCCGCAACCCGATATTATTTATTTATAATTAT \\
\hline (5'-FAM) C-MYC 5'-tail & ATAATTATAAATAAATAATTGGGTGGGTAGGGTGGGTAAA \\
\hline Complementary c-MYC 5'-tail & TTTACCCACCCTACCCACCCATATTATTTATTTATAATTAT \\
\hline (5'-FAM) c-MYC 3'-tail & AAATGGGTGGGTAGGGTGGGTATAATTATAAATAAATAATA \\
\hline Complementary c-MYC 3'-tail & TATTATTTATTTATAATTATACCCACCCTACCCACCCATTT \\
\hline (5'-FAM) c-MYC No tail & TGAGGGTGGGTAGGGTGGGTAA \\
\hline Complementary c-MYC No tail & TTACССАСССТАСССАСССТСА \\
\hline (5'-FAM) C-KIT1 No tail & TGGGAGGGCGCTGGGAGGAGGG \\
\hline Complementary c-KIT1 No tail & СССТССТСССАGCGСССТСССА \\
\hline FRET: (5'-FAM/3'-TAMARA) c-KIT1 & AGGGAGGGCGCTGGGAGGAGGGGC \\
\hline FRET: Complementary c-KIT1 & GCCССTCCTCCCAGCGCССTCCCT \\
\hline FRET: (5'-FAM/3'-TAMARA) hTELO & GGGTTAGGGTTAGGGTTAGGG \\
\hline FRET: Complementary hTELO & СССТАAСССТАACССТАACCC \\
\hline (5'-Cy5) rDNA-1 3'-tail & AAAGGGGCCGGGGGTGGGGTCGGCGGGGATAATTATAAATAAATAATA \\
\hline (5'-Cy5) rDNA-3 5'-tail & ATAATTATAAATAAATAATAGGGAGGGAGACGGGGGGG \\
\hline rDNA-2 No tail & AGGGTCGGGGGGTGGGGCCCGGGCCGGGG \\
\hline rDNA-3 No tail & AGGGAGGGAGACGGGGGGG \\
\hline
\end{tabular}

Table S1. Sequences of the oligonucleotides used. Red sequences identify the sequence tails. 


\begin{tabular}{|c|c|c|}
\hline G4 sequence & $\begin{array}{c}\text { CSB-FL } \\
(0.5-40 \mathrm{~min})\end{array}$ & $\begin{array}{l}\text { NO CSB-FL } \\
(0.5-40 \mathrm{~min})\end{array}$ \\
\hline $\begin{array}{l}\text { rDNA-1 } \\
\text { 5'-tail }\end{array}$ & $24.6^{\star \star \star \star}$ & $8^{\star \star \star \star}$ \\
\hline $\begin{array}{l}\text { rDNA-2 } \\
\text { 5'-tail }\end{array}$ & $61.1^{*}$ & $45.7^{*}$ \\
\hline $\begin{array}{l}\text { cKIT1 } \\
\text { 5'-tail }\end{array}$ & 45.1 & 40.6 \\
\hline $\begin{array}{l}\text { hTELO } \\
\text { 5'-tail }\end{array}$ & 41.2 & 49.4 \\
\hline $\begin{array}{l}\text { HRAS } \\
\text { 5'-tail }\end{array}$ & 69.8 & 67.8 \\
\hline $\begin{array}{l}\text { cMYC } \\
\text { 5'-tail }\end{array}$ & 36.3 & 28.3 \\
\hline $\begin{array}{l}\text { mut-cMYC } \\
\text { 5'-tail }\end{array}$ & 68.9 & 63.3 \\
\hline $\begin{array}{l}\text { cMYC } \\
\text { 3'-tail }\end{array}$ & 52.7 & 59.2 \\
\hline $\begin{array}{l}\text { rDNA-1 } \\
\text { No tail }\end{array}$ & 24.1 & 24.6 \\
\hline $\begin{array}{l}\text { CMYC } \\
\text { No tail }\end{array}$ & 38.1 & 39.2 \\
\hline $\begin{array}{l}\text { cKIT1 } \\
\text { No tail }\end{array}$ & 34.8 & 42.9 \\
\hline
\end{tabular}

Table S2. Quantification of the gel-based resolvase assay gels testing a panel of different G4forming sequences represented as percentage of ds formation in presence or absence of CSB-FL. All the results were based on the average of three independent experiments. Significance was calculated based on a two-tailed Student's t-test. Asterisks indicate statistical difference at 95\% confidence levels $(\mathrm{Cl})$ between presence or absence of the proteins. ${ }^{*} \mathrm{p}<0.05,{ }^{* * * *} \mathrm{p}<0.0001$. 


\begin{tabular}{|c|c|c|}
\hline G4 sequence & $\begin{array}{c}\text { CSB-HD } \\
(\mathbf{0 . 5 - 4 0} \mathbf{~ m i n})\end{array}$ & $\begin{array}{c}\text { NO CSB-HD } \\
(\mathbf{0 . 5 - 4 0} \mathrm{min})\end{array}$ \\
\hline $\begin{array}{c}\text { rDNA-1 } \\
\text { 5'-tail }\end{array}$ & $37.6^{*}$ & $23.4^{\star}$ \\
\hline
\end{tabular}

Table S3. Quantification of the gel-based helicase assay gels testing a panel of different G4forming sequences represented as percentage of ds formation in presence or absence of CSB-HD. All the results were based on the average of three independent experiments. Significance was calculated based on a two-tailed Student's t-test. Asterisks indicate statistical difference at 95\% confidence levels $(\mathrm{Cl})$ between presence or absence of the proteins. ${ }^{*} p<0.05,{ }^{* \star \star *} p<0.0001$.

\begin{tabular}{|l|l|}
\hline NAME & SEQUENCE (5' $\rightarrow$ 3') \\
\hline rDNA-1 G4 template & $\begin{array}{l}\text { TCTGCTTTGGGAACCCGAGAGGAGCGCTTATGGGGCCGGGGGTGG } \\
\text { GGTCGGCGGGGGATCAGCCGAGCAGCCGGCACTCTAGCTCTAG }\end{array}$ \\
\hline rDNA-2 G4 template & $\begin{array}{l}\text { TCTGCTTTGGGAACCCGAGAGGAGCGCTTATGGGTGGCGGGGGGG } \\
\text { AGAGGGGGGGCTCAGCCGAGCAGCCGAGCACTCTAGCTCTAG }\end{array}$ \\
\hline Primer (Cy5) & CTAGAGCTAGAGTGTCGGC \\
\hline rDNA-4 bimolecular 5'-tail & TAATAGGGGCCGGGGGTGGGGT \\
\hline (5'-Cy5) ssDNA & GGCATAGTGCGTGGGCG \\
\hline (5'-Cy5) O. nova G4 5'-tail & ATAATTATAAATAAATAATGGGGTTTTGGGG \\
\hline $\begin{array}{l}\text { Complementary O. nova G4 5'- } \\
\text { tail }\end{array}$ & CCCCAAAACCCCATTATTTATTTATAATTAT \\
\hline (5'-Cy5) rDNA-1 mut. 5'-tail & ATAATTATAAATAAATAATAGGTGCCGTGGTTGGTGTCGTCGGTGAAA \\
\hline
\end{tabular}

Table S4. Sequences of the oligonucleotides used. Red sequences identify the tails. Blue sequences indicate the G4-forming regions within the substrates used for polymerase stop assays and the green sequences are complementary to the primer used. 